\title{
The combination therapy of HIF1a inhibitor LW6 and cisplatin plays an effective role on anti-tumor function in A549 cells
}

\author{
L. MAI*, M. LUO, J. J. WU, J. H. YANG, L. Y. HONG \\ Department of Respiratory Medicine, Affiliated Hospital of Guilin Medical University, Guilin 541001, China \\ *Correspondence: mailin710@163.com
}

Received September 21, 2018 / Accepted April 28, 2019

\begin{abstract}
Hypoxia-inducible factor $1 \alpha$ (HIF1 $\alpha$ ) has been demonstrated to be involved in the resistance of various human cancer cells to chemotherapies. However, correlation between HIF1 $\alpha$ and sensitivity of human non-small cell lung cancer (NSCLC) cells to cisplatin has not been illuminated. The aim of present study was to investigate the effects of HIF1a on drug resistance in NSCLC cells. A549 cells were incubated in $21 \%$ or $0.5 \% \mathrm{O}_{2}$ followed by the assessment of HIF1 $\alpha$ level with qRT-PCR and western blot, and ROS levels by DCFH-DA assays. Effects of hypoxia or HIF1a inhibitor LW6 on the proliferation and apoptosis of A549 cells were evaluated via CCK-8 and flow cytometry assays. $\mathrm{IC}_{50}$ of A549 cells to cisplatin was determined by MTT assay. The mitochondrial membrane potential (MMP) was measured via JC-1 staining. Moreover, the expression of apoptosis related protein (Bcl-2, Bax) and drug resistance related proteins (MDR1, MRP1) were measured by western blotting. Exposure of A549 cells to $1 \% \mathrm{O}_{2}$ significantly upregulated HIF1a expression, maintained cell viability to cisplatin but decreased the ROS level, which promoted chemoresistance to cisplatin. LW6-treated A549 cells showed an increase in ROS level that blocked the hypoxia induced resistance to cisplatin and in addition, decreased expression of MDR1 and MRP1 in cisplatin-treated cells. This study revealed that hypoxia-improved cisplatin chemoresistance of NSCLC cells by regulated MDR1 and MRP1 expression via HIF1a/ROS pathway is reversed by LW6, suggesting that LW6 may act as effective sensitizer in chemotherapy for NSCLC.
\end{abstract}

Key words: non-small cell lung cancer, HIF1 $\alpha$, LW6, sensitivity, cisplatin

Non-small cell lung cancer (NSCLC), characterized by high resistance to chemotherapy and poor survival rate, is accounting for more than 85 percent of all lung cancers [1, $2]$. Despite the enormous progress in medical diagnostic and therapeutic strategies, NSCLC remains one of the most lethal diseases worldwide $[3,4]$. Chemoresistance of NSCLS cells to various anti-tumor agents is the leading cause of treatment failure. Therefore, exploring the underlying mechanisms of chemoresistance of NSCLC cells has become the most urgent issue in the clinical therapy. Accumulating evidences have revealed that hypoxia microenvironment exists in many different types of tumors, suggesting that hypoxia may play a critical role in the survival and metabolism of cancers [5-7]. Hypoxia inducible factor-1 $\alpha$ (HIF1 $\alpha$ ), an important mediator of cell adaption to hypoxia, was reported to be involved in the progression of various cancers, including colorectal cancer, bladder cancer and breast cancer [8-11]. However, the effects of HIF1a on non-small cell lung cancer (NSCLC) remain controversial.
HIF1 1 , a heterodimer consists of $\mathrm{O}_{2}$-regulated a subunit and $\mathrm{O}_{2}$-independent $\beta$ subunit, was reported to promote tumor growth by interacting with various cellular signaling pathway, such as von Hippel-Lindau protein (pVHL), PI3K/ Akt/mTOR and RAS/RAF/MEK/ERK kinase cascade[12]. In addition, elevated HIFla expression was demonstrated to correlate with tumor drug resistance, anti-apoptosis and poor survival rate [13]. Recently, highly expressed HIF1 a was also revealed in NSCLC tissues [14], and previous studies have suggested that polymorphisms of HIF1a gene were significantly associated with NSCLC outcomes in patients with early stage disease [15], implying that HIF1a could be an effective therapeutic target for NSCLC. LW6, as a HIF1a inhibitor, has been reported to serve as a new potent inhibitor of various cancers, such as breast, colon and lung cancer [16-18]. Thus, LW6 may be a potential new anti-tumor agent.

Cisplatin is one of the most widely used drugs in NSCLC chemotherapy, however, the occurrence of chemoresistance still scourged majority NSCLC patients. Evidences 
showed that cisplatin exposure in vivo could induce oxidative damage in cancer tissues, implying that oxidative stress may participate in the cisplatin anticancer effects $[19,20]$. Therefore, reactive oxygen species (ROS), predominantly produced by mitochondria, were considered to mediate the cytotoxic effects of cisplatin [21]. However, whether hypoxia, HIF1a and ROS contribute to cisplatin induced cytotoxicity in cancer remains undetermined.

In the present study, we demonstrated that highly expressed HIF $1 \alpha$ induced by hypoxia decreased cellular ROS level, which prevented NSCLC cells apoptosis from the cytotoxic cisplatin exposure and increased the drug resistance of NSCLC. Whereas, the application of HIF1a inhibitor LW6 reversed these effects under hypoxia which suggested that LW6 may be an important sensitizer of tumor cells to cisplatin.

\section{Materials and methods}

Cell culture and treatment. The human NSCLC cell line A549 was purchased from the American Type Culture Collection (Manassas, VA, USA) and cultured at $37^{\circ} \mathrm{C}$ in Dulbecco's modified Eagle's medium (DMEM, Gibco, USA) with $1 \%$ penicillin/streptomycin and $15 \%$ fetal bovine serum (FBS, Invitrogen, Carlsbad, USA) under normoxic $\left(21 \% \mathrm{O}_{2}\right.$, $74 \% \mathrm{~N}_{2}$ and $\left.5 \% \mathrm{CO}_{2}\right)$ or hypoxic $\left(1 \% \mathrm{O}_{2}, 94 \% \mathrm{~N}_{2}\right.$, and $5 \%$ $\mathrm{CO}_{2}$ ) condition.

LW6 $(10 \mu \mathrm{M})$, an inhibitor of HIF1a, was purchased from Merck Millipore (Darmstadt, Germany). The cells treated with LW6 for $12 \mathrm{~h}$ were exposed to normoxia or hypoxia for $48 \mathrm{~h}$ and then analyzed. To verify that ROS are the mediators for HIFla induced resistance to cisplatin, ROS scavenger, $\mathrm{N}$-acetyl-L-cysteine (NAC, purchased from Selleck, USA) and its agonist, sanguinarine (Sigma-Aldrich, USA) were both applied for following experiments.

Quantitative real-time PCR (qRT-PCR) assay. Total RNA of A549 cells was extracted by using TRIzol reagent (Takara, Japan). Then $1 \mu \mathrm{g}$ of total RNA was reversely transcribed into cDNA by using Takara RT kit following the instructions provided by the manufacturer. Real-time qPCR for the cDNA products was carried out via an ABI Prism 7700 sequence detection system (PE Applied Biosystems) with the following protocols: $95^{\circ} \mathrm{C}, 3 \mathrm{~min} ; 40$ cycles of $95^{\circ} \mathrm{C}$, $20 \mathrm{~s}, 60^{\circ} \mathrm{C} 45 \mathrm{~s}$, and $72^{\circ} \mathrm{C} 2 \mathrm{~min} ; 72^{\circ} \mathrm{C} 10 \mathrm{~min}$. The sequence of GAPDH primers were: $\mathrm{F}, 5^{\prime}$-TGTTCGTCATGGGTGTGAAC-3', R, 5'-ATG GCA TGG ACT GTG GTC AT-3'; the sequences of HIF $1 a$ primers were: F, 5'-CTG ACC CTG CAC TCA ATC AA-3', R, 5'-CTT TGC TTC TGT GTC TTC AGC AGC A-3'. All primers were designed and obtained from Shenggong, China and the mRNA expression of HIFla was normalized to GAPDH.

Western Blot assay. Cellular protein extracts of A549 cells under normoxia or hypoxia were extracted by a cell lysis buffer $(0.5 \mathrm{M}$ Tris, $250 \mathrm{mM} \mathrm{NaCl}, 0.1 \%$ Nonidet P-40, $0.2 \mathrm{M} \mathrm{Na}_{3} \mathrm{VO}_{4}, 0.2 \mathrm{M} \mathrm{NaF}$ ), supplemented with a protease inhibitor. Protein concentration was determined by a BCA kit (Pierce, Rockford) and $40 \mu \mathrm{g}$ of total proteins were then separated by $10 \%$ SDS-PAGE. Subsequently, proteins were electrophoretic transferred into polyvinylidene difluoride (PVDF) membranes (Millipore, Bedfordshire, UK). After blocking with $5 \%$ low fat dried milk at room temperature for $2 \mathrm{~h}$, membranes were incubated with primary antibodies overnight. HIF1a (Rabbit, ab51608, Abcam, 1:500), Bcl-2 (Rabbit, ab196495, Abcam, 1:1000), Bax (Rabbit, ab32503, Abcam, 1:2000), MDR1 (Rabbit, ab129450, Abcam, 1:2000), MRP1 (Rabbit, ab233383, Abcam, 1:1000), Actin (Rabbit, ab5694, Abcam, 1:5000). Then, the blots were incubated with horseradish peroxidase conjugated donkey-anti-rabbit secondary antibodies (IgG-HRP, ab6802, Abcam, 1:2000). Finally, membranes were visualized by enhanced chemiluminescent reagents (ECL, Germany).

Measurement of intracellular ROS (DCFH-DA assay). Intracellular ROS levels of A549 cells under normoxia or hypoxia were assessed by the OxiSelect ${ }^{\mathrm{TM}}$ Intracellular ROS Assay Kit (Cell Biolabs, STA342, USA) according to the protocols obtained from manufacturers. Briefly, A549 cells were treated with a cell permeable fluorescent 2',7'-dichlorodihydrofluorescin diacetate (DCFH-DA), which can be degraded into non-fluorescent 2',7'-DCFH. The DCFH could be oxidized by cellular ROS into fluorescent dichlorodihydrofluorescin (DCF). Therefore, the fluorescent intensity is proportional to the intracellular ROS levels.

CCK-8 assay. The effects of normoxia or hypoxia on proliferation of A549 cells were evaluated by Cell Counting Kit- 8 (CCK-8) assay. Briefly, A549 cells were plated into 96-well plates at a density of $2 \times 10^{3}$ cells/well under normoxia or hypoxia, and cell proliferation at $0,24,48,72$ and $96 \mathrm{~h}$ was assess using a CCK-8 detection kit (Beyotime Institute of Biotechnology, China) according to the manufacturer's instructions.

Flow cytometry analysis. Following exposure to normoxia, hypoxia or treatment with cisplatin, A549 cells were harvested using trypsinization and then twice washed with PBS. After staining with Annexin V-fluorescein isothiocyanate (FITC) and propidium iodide (PI) in the dark, A549 cells were subjected to apoptosis analysis by a BectonDickinson FACS Calibur Flow Cytometer.

MTT assay. MTT assay was performed to measure $\mathrm{IC}_{50}$ value of cisplatin in A549 cells exposed under normoxia or hypoxia. A549 cells were seeded into 96-well plates at a density of $2 \times 10^{3}$ cells/well, followed by the incubation of various concentration of cisplatin $(0.001,0.01,0.1,1,10$, 100 and $1000 \mu \mathrm{M})$ and cultured under normoxic or hypoxic condition for $24 \mathrm{~h}$. Then, cells were incubated with $20 \mu \mathrm{l}$ of $5 \mathrm{mg} / \mathrm{ml}$ MTT reagent and cultured for a further $4 \mathrm{~h}$. After treatment with $200 \mu \mathrm{l}$ dimethyl sulfoxide for $15 \mathrm{~min}$, the 96-well plates were analyzed by a microplate reader (Thermo Scientific, Waltham, MA, USA) at $450 \mathrm{~nm}$.

Determination of mitochondrial membrane potential (MMP). The decline of MMP is a landmark event in the early stage of cell apoptosis. In this study, JC-1 staining was performed to measure the MMP of A549 cells under 
normoxic or hypoxic condition. Briefly, A549 cells were collected and washed twice with PBS, and then incubated with JC-1 $(5 \mu \mathrm{M})$ for $15 \mathrm{~min}$ at $37^{\circ} \mathrm{C}$. Subsequently, the signals of A549 cells were detected by a BZ-9000 fluorescence microscope (Keyence, Osaka, Japan).

Statistical analysis. Statistical analysis was performed using GraphPad Prism v5.01. Comparison between two groups or multiple groups was analyzed with the Student's t-test or one-way analysis of variance (ANOVA) test. Differences between means were considered significant if $\mathrm{p}<0.05$. All experiments were repeated at least three times.

\section{Results}

Hypoxia increased HIF1a expression and cell viability, while decreased ROS expression in A549 cells. To investigate the effects of hypoxia with the connection to HIF1a expression, ROS level and cell viability, A549 cells were cultured under normoxic $\left(21 \% \mathrm{O}_{2}, 74 \% \mathrm{~N}_{2}\right.$ and $\left.5 \% \mathrm{CO}_{2}\right)$ or hypoxic $\left(1 \% \mathrm{O}_{2}, 5 \% \mathrm{CO}_{2}\right.$, and $\left.94 \% \mathrm{~N}_{2}\right)$ conditions for indicated time. qRT-PCR and western blot analysis showed that hypoxia remarkably upregulated the mRNA and protein levels of HIF1 $\alpha$ compared with normoxia group (Figures 1A and B).
A

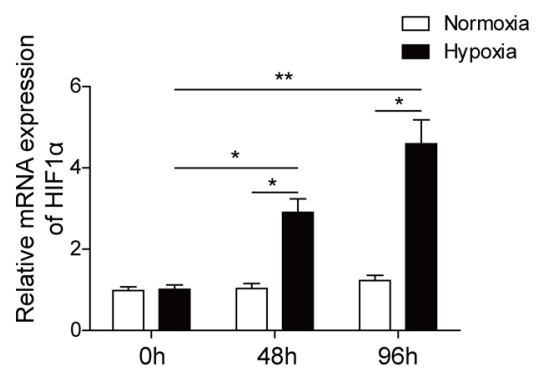

C

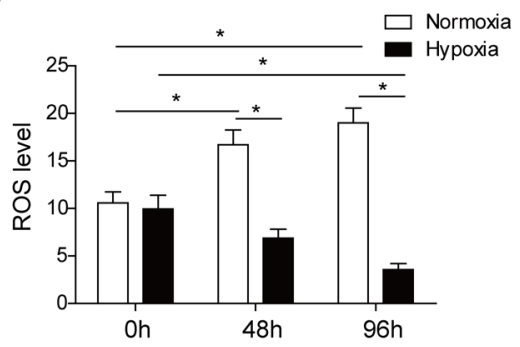

B

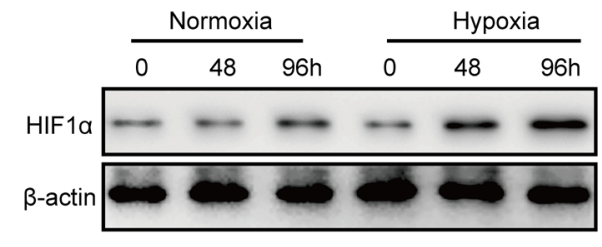

D

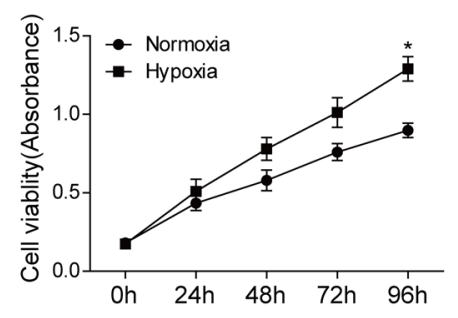

E
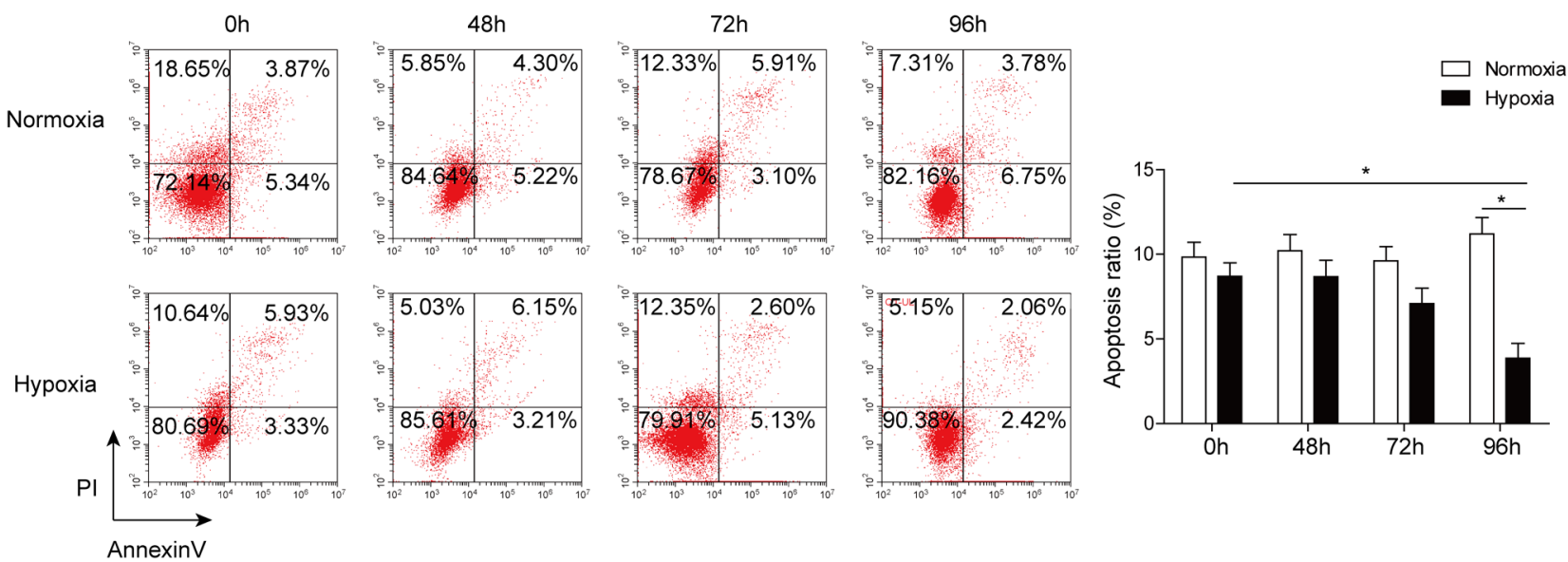

Figure 1. Hypoxia increased HIF1a expression and cell viability, while decreased ROS level in A549 cells. A) The relative mRNA expression or B) protein expression of HIF1a in A549 cells under normoxia $\left(21 \% \mathrm{O}_{2}, 74 \% \mathrm{~N}_{2}\right.$ and $\left.5 \% \mathrm{CO}_{2}\right)$ and hypoxia $\left(1 \% \mathrm{O}_{2}, 94 \% \mathrm{~N}_{2}\right.$, and $\left.5 \% \mathrm{CO}_{2}\right)$ was measured by qRT-PCR or western blot, respectively, at 0,48 and $96 \mathrm{~h} .{ }^{*} \mathrm{p}<0.05$ and ${ }^{\star *} \mathrm{p}<0.01$ vs. Normoxia group. C) ROS level was detected in A549 cells following 0,48 , and $96 \mathrm{~h}$ exposure to hypoxia at $37^{\circ} \mathrm{C}$. ${ }^{\star} \mathrm{p}<0.05$ vs. Normoxia group. D) Cell proliferation and E) apoptosis was measured in A549 cells under hypoxia by CCK8 assay and flow cytometry analysis, respectively. ${ }^{\star} \mathbf{p}<0.05$ vs. Normoxia group. The results are presented as the mean \pm standard error of three independent experiments. 
DCF-DA assay was performed to assess the level of reactive oxygen species (ROS). In contrast to HIF1a, the intracellular ROS level was inhibited under hypoxia (Figure 1C). Subsequently, CCK-8 assay and flow cytometry analysis was used to evaluate cell viability and apoptosis, respectively. Results showed that A549 cells incubated with hypoxia presented better activity (Figure 1D) and less cell apoptosis (Figure 1E). These results suggested that hypoxia could increase HIF1a expression, decrease ROS level and maintain cell viability.

HIFla induced by hypoxia decreased the sensitivity of A549 cells to cisplatin. Cisplatin is a common chemotherapy drug in the clinical therapy of NSCLC. However, the therapeutic effects of cisplatin were trapped as a result of chemoresistance in NSCLC. Since HIF1a was reported to be involved in the chemoresistance of various human cancers, we assessed the role of HIF1a in NSCLC cells to cisplatin. The $\mathrm{IC}_{50}$ values of cisplatin in A549 cells exposed under normoxic or hypoxic conditions were evaluated by MTT assay, and the results showed that exposure to hypoxia increased the $\mathrm{IC}_{50}$ value of cisplatin in A549 cells in contrast to cells under normoxia (Figure 2A). CCK-8 assay and flow cytometry analysis were performed to assess the effects of cisplatin on A549 cells proliferation and apoptosis with normoxia or hypoxia, respectively. Under normoxic condition, cisplatin treatment remarkably inhibited cell proliferation and promoted cell apoptosis. Whereas, hypoxia recov-
A

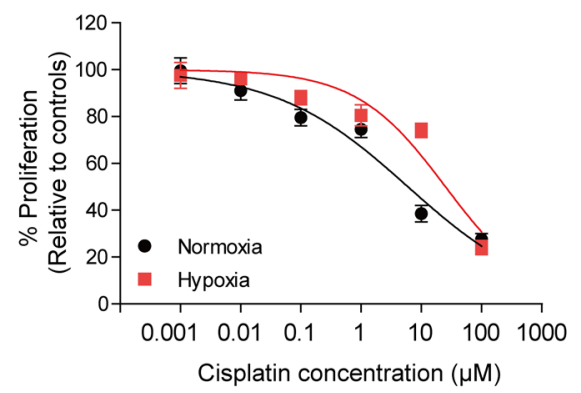

C
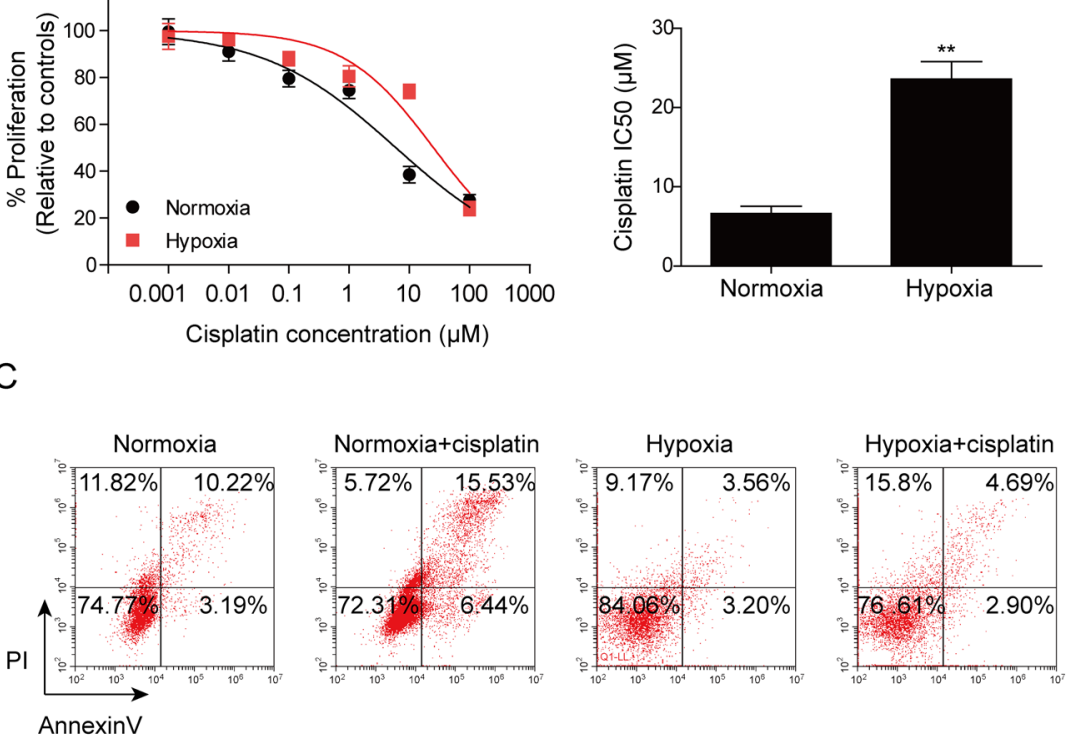

B
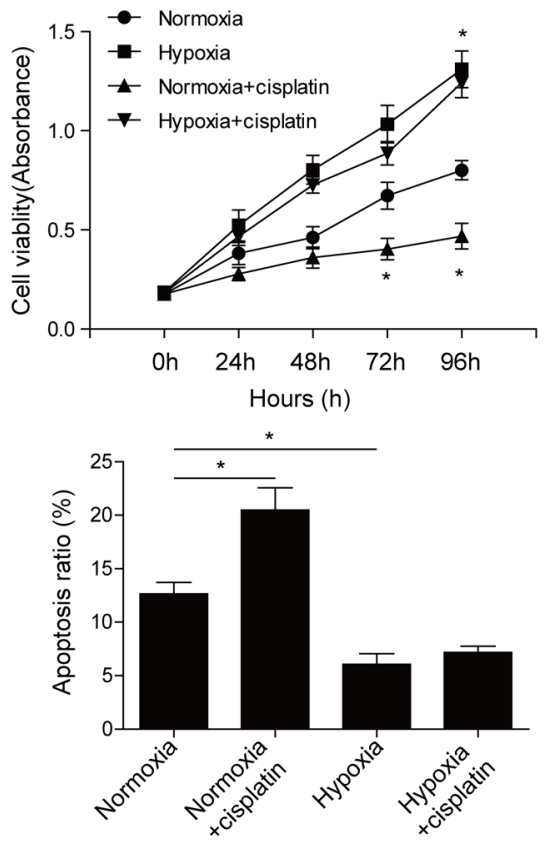

$\mathrm{D}$
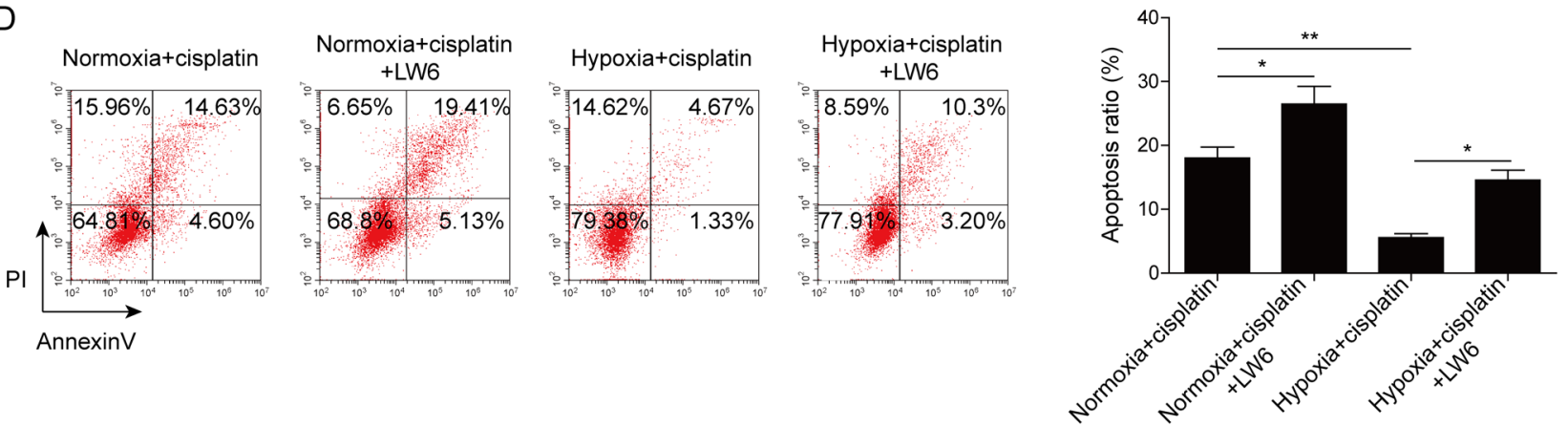

Figure 2. Sensitivity of A549 cells to cisplatin was attenuated by HIF1a. A) A549 cells treated with various concentrations of cisplatin (0.001, 0.01, $0.1,1,10,100$ and $1000 \mu \mathrm{M})$ in normoxic or hypoxic conditions for 24 hours were subjected for MTT analysis to determine the IC ${ }_{50}$ value of cisplatin. ${ }^{* *} \mathrm{p}<0.01$ vs. Normoxia. (Normoxia: $\mathrm{IC}_{50}$ was $6 \mu \mathrm{M}$; Hypoxia: $\mathrm{IC}_{50}$ was $24 \mu \mathrm{M}$ ). B) CCK8 analysis of cell viability in A549 cells under normoxia or hypoxia with or without the presence of cisplatin. ${ }^{\star} \mathrm{p}<0.05 \mathrm{vs}$. Normoxia group and $\# \mathrm{p}<0.05$ vs. Normoxia group. C) Flow cytometry analysis of apoptosis rate in A549 cells under normoxia or hypoxia with or without cisplatin. ${ }^{*} \mathbf{p}<0.05$ vs. Normoxia group. D) The effect of LW6 on the apoptosis of A549 cells ex-

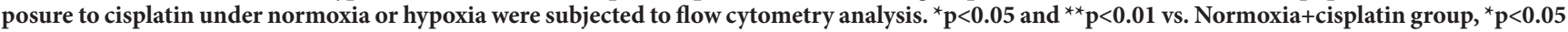
vs. Hypoxia+cisplatin group. Values are expressed as the mean \pm standard error from three different experiments. 
ered A549 cells viability and reduced apoptosis (Figures 2B and $2 \mathrm{C}$ ). These results implied that hypoxia could enhance chemoresistance of A549 cells to cisplatin. However, when pre-treating A549 cells with HIF1a inhibitor LW6, the effects of hypoxia on chemoresistance was reversed (Figure 2D). Together, these findings suggested that hypoxia could increase drug resistance to cisplatin by upregulating HIF1a expression in A549 cells.

HIF1a enhanced chemoresistance of A549 cells to cisplatin by downregulating ROS level. Several studies have implied that the anti-tumor effects of cisplatin may be related to ROS-mediated apoptosis. To further explore whether ROS are the mediators for HIFla-induced resistance to cisplatin, the following experiments were performed. A549 cells were pre-treated with HIF1 $\alpha$ inhibitor (LW6) followed by an exposure to normoxia or hypoxia, and then the ROS production and MMP of A549 cells were assessed. The results showed that LW6 treatment significantly increased the ROS level both in normoxic and hypoxic conditions (Figure 3A). Similarly, the MMP of JC-1 staining also indicated that LW6 treatment resulted in a significant reduction of MMP (Figure 3B). In addition, flow cytometry analysis was performed to evaluate the effects of HIF1a inhibition on cell apoptosis caused by cisplatin. As shown in Figure 3C, HIF1a inhibition induced by LW6 promoted cell apoptosis both in normoxic or hypoxic conditions. In addition, the ROS scavenger (NAC) and its agonist (sanguinarine) were adopted for mechanistic experiments. As expected, sanguinarine significantly caused the promotion of ROS level, while NAC obviously increased the ROS level (Figure 3D). Besides, the MMP and flow cytometry analysis also implied that sanguinarine markedly reversed the suppressive effects of LW6 on cell injury, while NAC further promoted the function of LW6 (Figures 3E and $3 \mathrm{~F}$ ). Taken together, these findings suggested that upregulation of HIFla induced by hypoxia may increase cisplatin resistance by decreasing ROS level in A549 cells.

HIF1 a inhibitor LW6 combined with cisplatin promoted the sensitivity of A549 cells. In order to investigate the potential therapeutic effects of LW6 in NSCLC, we examined the $\mathrm{IC}_{50}$ value of cisplatin under hypoxia with or without LW6 by MTT assay which caused that the $\mathrm{IC}_{50}$ in $\mathrm{A} 549$ cells under hypoxia without LW6 was significantly higher than in cells pre-treated with LW6 (Figure 4A). Moreover, the expression of apoptosis related proteins (Bcl-2 and Bax) and drug resistance proteins (MDR1 and MRP1) were measured by western blot assay in the A549 cells treated with cisplatin or/and LW6 under normoxia or hypoxia. Results showed that hypoxia increased the Bcl-2 expression, and decreased the Bax expression following exposure to cisplatin, compared with normoxia. This effect was reversed by the application of LW6 (Figure 4B). In addition, the increased expression of MDR1 and MRP1 induced by hypoxia was also reversed by the treatment of LW6 (Figure 4B). All these finding suggested that LW6 may play a vital role in sensitivity of A549 cells to cisplatin, which could block the progression of NSCLC.

\section{Discussion}

The present study focused the relationship of hypoxia, HIF la expression, ROS level and chemoresistance of NSCLC to cisplatin. We found that hypoxia exposure could increase the expression level of HIF $1 \alpha$, while decrease the level of ROS. Meanwhile, hypoxia-induced HIF1a upregulation resulted in a significant chemoresistance of A549 cells to cisplatin. However, these effects were obviously reversed by the application of LW6, a novel HIF1a inhibitor. Mechanistically, our data also implied that ROS were the mediators for HIF1a induced chemoresistance to cisplatin using ROS scavenger or its agonist, to be involved in cell apoptosis. Altogether, our study demonstrated that the combination therapy of LW6 and cisplatin could enhance the sensitivity of A549 cells to cisplatin, providing a novel potential therapeutic strategy for NSCLC patients.

As one of the typical features of tumor microenvironment, hypoxia (low oxygen), caused by abnormal blood vessel growth, is frequently observed in various types of human cancers [22-24]. Previous studies in cancer cells and animals have suggested that hypoxic condition may contribute to the growth, metastasis and drug-resistance of tumors [22, 25]. HIF1a, a critical transcription factor, was revealed to be activated by the hypoxic condition in multiple human cancers. For example, it was reported that HIFla was upregulated in pancreatic cancer (PC) cell lines, and transfected with HIF1a could potentiate the survival and tumorigenesis of $\mathrm{PC}$ cells in vitro and in vivo [26]. Moreover, Guo et al. have reported that hypoxia exposure increased the levels of HIF1a and p53 of A549 cells [27], which was consistent with our result.

Cisplatin is one of the most common drugs used for NSCLC treatment, however, its curative effects are limited by the chemoresistance. Hypoxia of tumor microenvironment has been considered to be the primary reason of chemoresistance, and evidences have shown that HIF1a could regulate the cellular response to hypoxic stress by mediating the expression of target genes, which is associated with angiogenesis, resistance, invasion and metastasis [28]. Moreover, inhibition of HIF $1 \alpha$ was demonstrated to attenuate metastasis of breast cancer cells and increase the sensitivity of tumors to chemotherapy [29]. Recently, panobinostat (histone deacetylase inhibitor) was shown to reduce hypoxia-induced cisplatin resistance of NSCLC cells by destabilizing HIF1a expression [1], implying that HIFla may play a key role in the drugresistance of NSCLC. In the present study, we found that hypoxia induced the upregulation of HIF1a, cell viability and chemoresistance was increased as compared with normoxia, suggesting that hypoxia may enhance chemoresistance of NSCLC cells via increasing HIF1a expression.

ROS are byproducts generated during the normal cellular metabolism, however, excessive production of ROS may cause detrimental effects in cells [30-32]. The cellular accumulation of ROS could alter the MMP and impair the respiratory chain which then activates the apoptotic pathway [33]. 
A

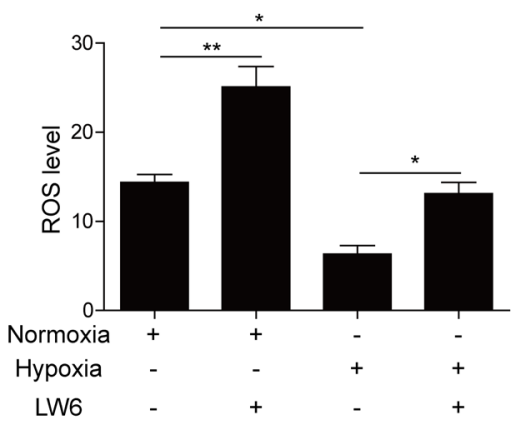

B

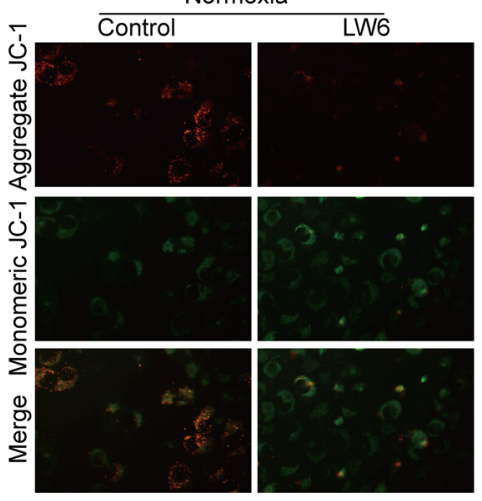

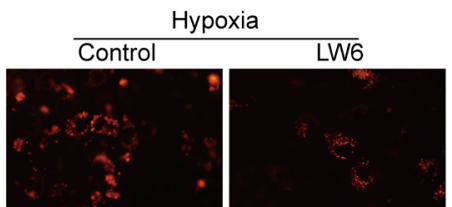
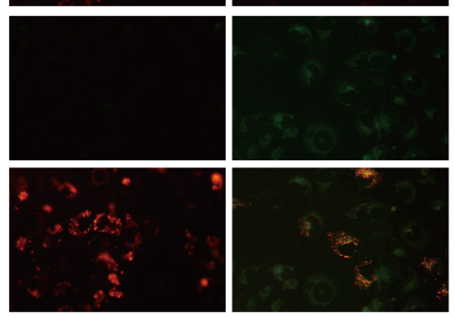

C

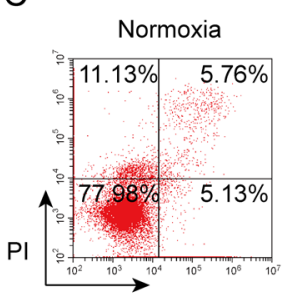

AnnexinV

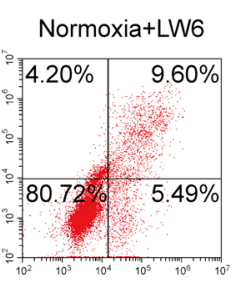

Hypoxia

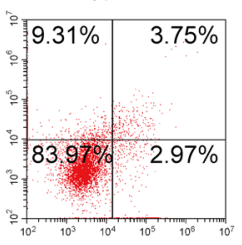

Hypoxia+LW6

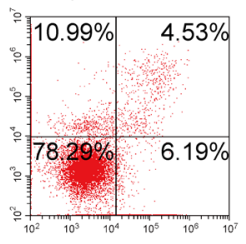

Normoxia

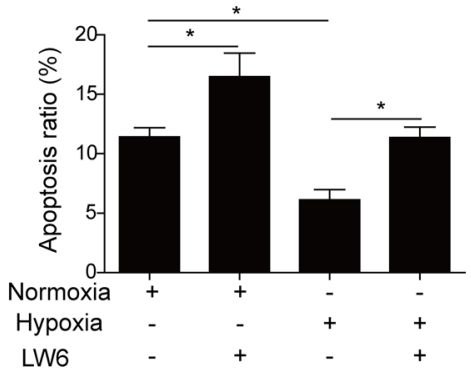

D

E

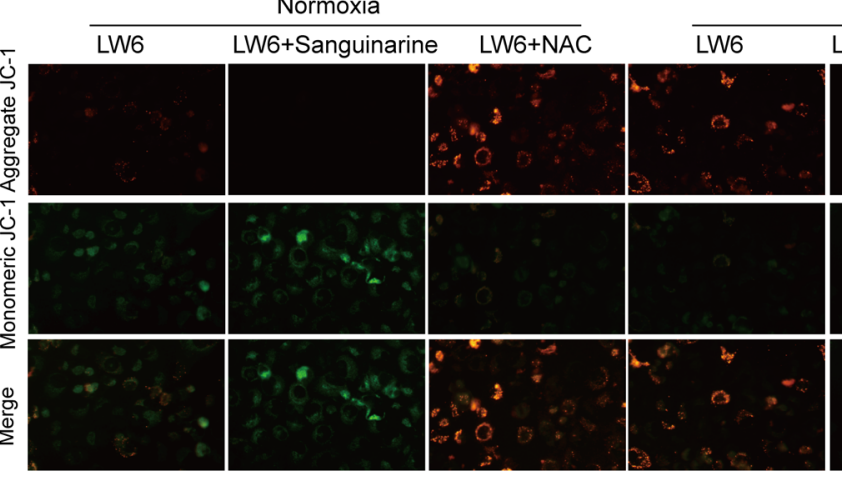

Hypoxia

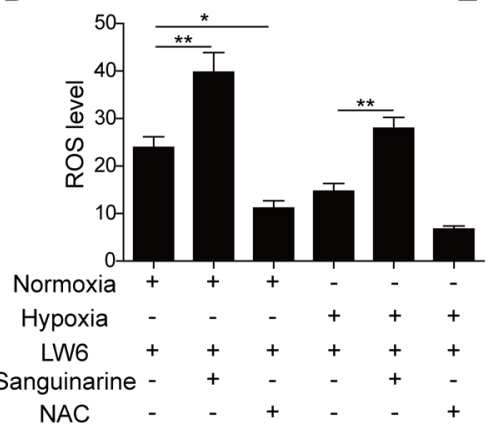

W6+Sanguinarine

LW6+NAC

F

Normoxia

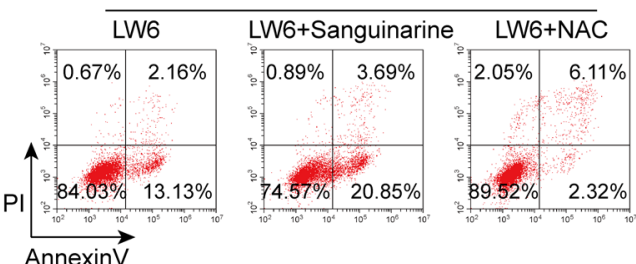

Hypoxia

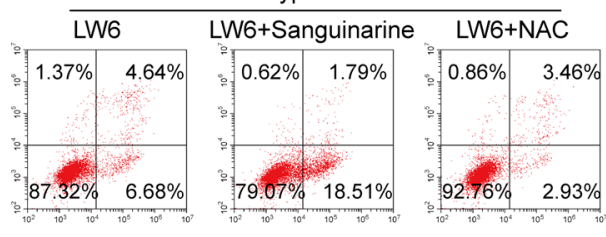

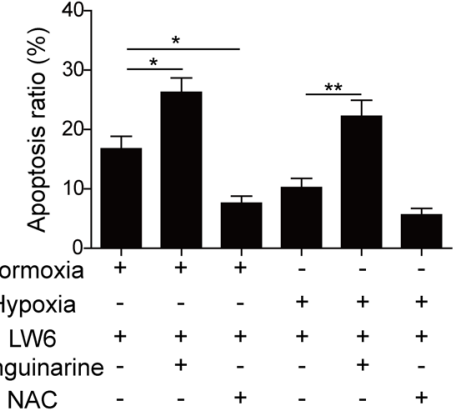

Figure 3. HIF1 $\alpha$ attenuated the sensitivity of A549 cells to cisplatin by declining ROS level. A) ROS level was determined in A549 cells treated with or without LW6 under normoxic or hypoxic condition. ${ }^{\star} \mathrm{p}<0.05$ and ${ }^{\star *}$ p $<0.01$ vs. Normoxia group. ${ }^{\star}$ p $<0.05$ vs. Hypoxia group. B) After treating with LW6 $(20 \mu \mathrm{M})$ under normoxic or hypoxic conditions, the mitochondrial membrane potential (MMP) of A549 cells was detected by JC-1 staining. C) Cell apoptosis was determined using flow cytometry. ${ }^{*} \mathrm{p}<0.05$ vs. Normoxia and ${ }^{\star} \mathrm{p}<0.05$ vs. Hypoxia. D) ROS level was measured in A549 cells pre-treated with ROS scavenger or agonist. ${ }^{\star} \mathrm{p}<0.05$ and ${ }^{\star *} \mathrm{p}<0.01$ vs. Normoxia+LW6. ${ }^{* *} \mathrm{p}<0.01$ vs. Hypoxia+LW6. E) JC-1 staining was subjected to assess the mitochondrial membrane potential (MMP) of A549 cells. F) Cell apoptosis was determined by flow cytometry analysis. ${ }^{\star}$ p $<0.05$ vs. Normoxia+LW6. ${ }^{* *} \mathrm{p}<0.01$ vs. Hypoxia+LW6. Values are expressed as the mean \pm standard error from three different experiments. 
A

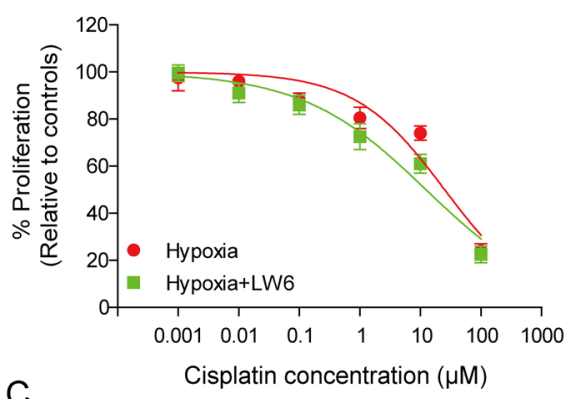

B

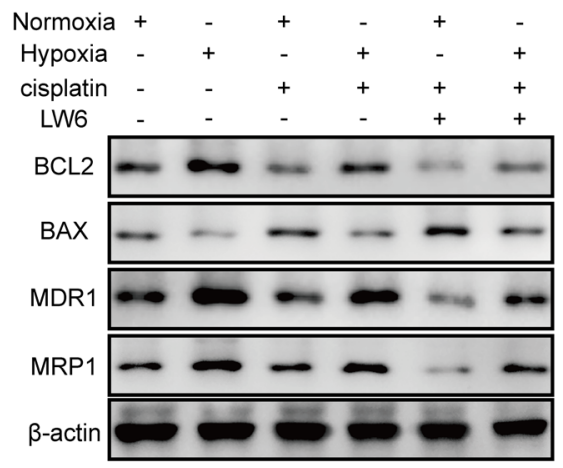

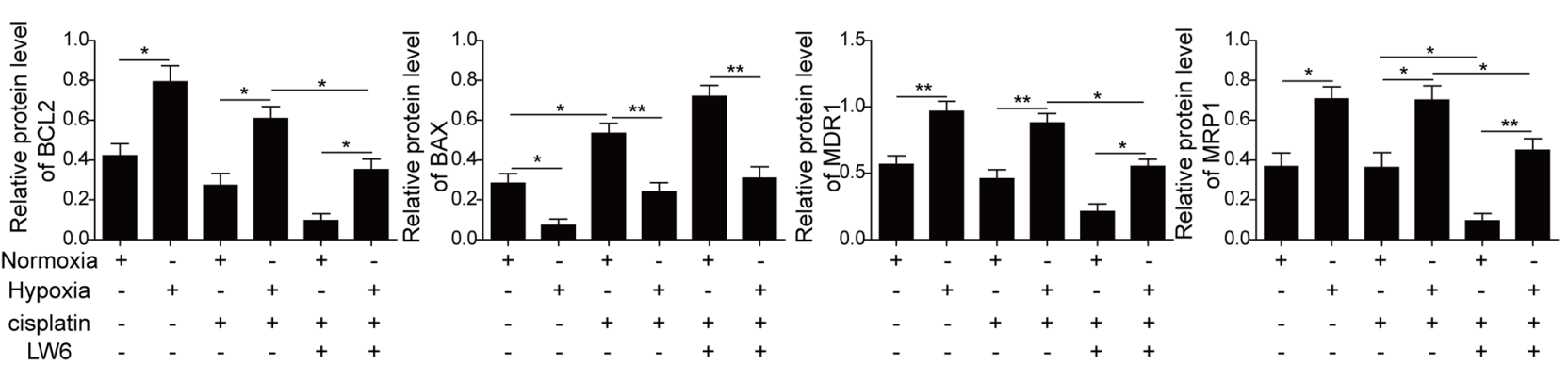

Figure 4. LW6 increased the sensitivity of A549 cells to cisplatin. A) A549 cells were cultured under hypoxic conditions following exposure with LW6 and then cells were subjected for MTT analysis to determine the $\mathrm{IC}_{50}$ of cisplatin in A549 cells. ${ }^{\star} \mathrm{p}<0.05$ vs. Hypoxia. (Hypoxia: $\mathrm{IC}_{50}$ was $24 \mu \mathrm{M}$; Hypoxia+LW6: $\mathrm{IC}_{50}$ was $12 \mu \mathrm{M}$ ). B and C) The protein expression of Bcl-2, Bax, MDR1 and MRP1 were measured in cisplatin or/and LW6 treated A549 cells under normoxia and hypoxia by western blot. $\beta$-actin was used as an internal control. ${ }^{*} p<0.05$ and ${ }^{*} p<0.01$ vs. Normoxia group, ${ }^{\star} p<0.05$ and ${ }^{* *} \mathrm{p}<0.01$ vs. Normoxia+LW6 group, ${ }^{*} \mathrm{p}<0.05$ or Hypoxia + cisplatin group, ${ }^{*} \mathrm{p}<0.05$ and ${ }^{* *} \mathrm{p}<0.01$ vs. Normoxia+cisplatin group. Results are presented as the mean \pm standard error of three independent experiments.

Recently, multiple studies have suggested that ROS accumulation was considered to be one of the potential mechanisms of cisplatin therapy in cancer cells [34]. In this present study, we revealed that the decline of ROS level induced by hypoxia was reversed by LW6 and increased ROS generation could sensitize NSCLC cells to cisplatin which ultimately induced apoptosis, implying ROS involvement in the cytotoxic effects of cisplatin, consistent with previous findings.

In conclusion, we ensured that hypoxia enhanced chemoresistance of A549 cells to cisplatin by modulating the expression of HIF1 $\alpha$ and ROS level. Thus, the combination therapy of HIF 1 a inhibitor LW6 and cisplatin may improve the sensitivity of A549 cells to chemotherapy and play an essential anti-tumor function in NSCLC.

Acknowledgements: This work was supported by Guangxi Natural Science Foundation (No.2015GXNSFBA139170).

\section{References}

[1] FISCHER C, LEITHNER K, WOHLKOENIG C, QUEHENBERGER F, BERTSCH A et al. Panobinostat reduces hypoxia-induced cisplatin resistance of non-small cell lung carcinoma cells via HIF-1alpha destabilization. Mol Cancer 2015; 14: 4. https://doi.org/10.1186/1476-4598-14-4
[2] ECONOMOPOULOU P, MOUNTZIOS G. Non-small cell lung cancer (NSCLC) and central nervous system (CNS) metastases: role of tyrosine kinase inhibitors (TKIs) and evidence in favor or against their use with concurrent cranial radiotherapy. Transl Lung Cancer Res 2016; 5: 588-598. https://doi.org/10.21037/tlcr.2016.12.06

[3] DEVAPATLA B, SHIDAL C, YADDANAPUDI K, DAVIS KR. Validation of syngeneic mouse models of melanoma and non-small cell lung cancer for investigating the anticancer effects of the soy-derived peptide Lunasin. F1000Res 201; 5: 2432. https://doi.org/10.12688/f1000research.9661.2

[4] KUMAR R, COLLINS D, DOLLY S, MCDONALD F, O'BRIEN MER et al. Targeting the PD-1/PD-L1 axis in non-small cell lung cancer. Curr Probl Cancer 2017; 41: 111-124. https://doi.org/10.1016/j.currproblcancer.2016.12.002

[5] KELLY NJ, VARGA JFA, SPECKER EJ, ROMEO CM, COOMBER BL et al. Hypoxia activates cadherin-22 synthesis via eIF4E2 to drive cancer cell migration, invasion and adhesion. Oncogene 2018; 37: 651-662. https://doi. org/10.1038/onc.2017.372

[6] MAHKAMOVA K, LATAR N, ASPINALL S, MEESON A. Hypoxia Increases Thyroid Cancer Stem Cell-Enriched Side Population. World J Surg 2018; 42: 350-357. https://doi. org/10.1007/s00268-017-4331-x 
[7] ZHA JM, XU XF, LI DP, GUI Q, LIANG RR et al. [Hypoxia promotes the growth and invasiveness of prostate cancer cells by down-regulating miR-132 in vitro]. Zhonghua Nan Ke Xue 2016; 22: 1071-1076.

[8] MURONO K, TSUNO NH, KAWAI K, SASAKI K, HONGO K et al. SN-38 overcomes chemoresistance of colorectal cancer cells induced by hypoxia, through HIF1alpha. Anticancer Res 2012; 32: 865-872.

[9] LIANG H, XIAO J, ZHOU Z, WU J, GE F et al. Hypoxia induces miR-153 through the IRE1alpha-XBP1 pathway to fine tune the HIF1alpha/VEGFA axis in breast cancer angiogenesis. Oncogene 2018; 37: 1961-1975. https://doi.org/10.1038/ s41388-017-0089-8

[10] JIANG ZF, WANG M, XU JL, NING YJ. Hypoxia promotes mitochondrial glutamine metabolism through HIF1alphaGDH pathway in human lung cancer cells. Biochem Biophys Res Commun 2017; 483: 32-38. https://doi.org/10.1016/j. bbrc.2017.01.015

[11] KOUKOURAKIS MI, KAKOURATOS C, KALAMIDA D, BAMPALI Z, MAVROPOULOU S et al. Hypoxia-inducible proteins HIF1alpha and lactate dehydrogenase LDH5, key markers of anaerobic metabolism, relate with stem cell markers and poor post-radiotherapy outcome in bladder cancer. Int J Radiat Biol 2016; 92: 353-363. https://doi.org/10.3109/0 9553002.2016.1162921

[12] TONG WW, TONG GH, LIU Y. Cancer stem cells and hypoxia-inducible factors (Review). Int J Oncol 2018; 53: 469-476. https://doi.org/10.3892/ijo.2018.4417

[13] WANG P, WAN W, XIONG S, WANG J, ZOU D et al. HIF1alpha regulates glioma chemosensitivity through the transformation between differentiation and dedifferentiation in various oxygen levels. Sci Rep 2017; 7: 7965. https://doi. org/10.1038/s41598-017-06086-2

[14] WANG C, HAN C, ZHANG Y, LIU F. LncRNA PVT1 regulate expression of HIF1alpha via functioning as ceRNA for miR199a5p in nonsmall cell lung cancer under hypoxia. Mol Med Rep 2018; 17: 1105-1110. https://doi.org/10.3892/ mmr.2017.7962

[15] LIU B, LIU Q, SONG Y, LI X, WANG Y et al. Polymorphisms of HIF1A gene are associated with prognosis of early stage non-small-cell lung cancer patients after surgery. Med Oncol 2014; 31: 877. https://doi.org/10.1007/s12032-0140877-8

[16] SONG JG, LEE YS, PARK JA, LEE EH, LIM SJ et al. Discovery of LW6 as a new potent inhibitor of breast cancer resistance protein. Cancer Chemother Pharmacol 2016; 78: 735-744. https://doi.org/10.1007/s00280-016-3127-2

[17] SATO M, HIROSE K, KASHIWAKURA I, AOKI M, KAWAGUCHI H et al. LW6, a hypoxia-inducible factor 1 inhibitor, selectively induces apoptosis in hypoxic cells through depolarization of mitochondria in A549 human lung cancer cells. Mol Med Rep 2015; 12: 3462-3468. https://doi.org/10.3892/ mmr.2015.3862

[18] LEE K, KANG JE, PARK SK, JIN Y, CHUNG KS et al. LW6, a novel HIF-1 inhibitor, promotes proteasomal degradation of HIF-1alpha via upregulation of VHL in a colon cancer cell line. Biochem Pharmacol 201; 80: 982-989. https://doi. org/10.1016/j.bcp.2010.06.018
[19] QUINTANILHA JCF, VISACRI MB, SOUSA VM, BASTOS LB, VAZ CO et al. Cisplatin-induced human peripheral blood mononuclear cells' oxidative stress and nephrotoxicity in head and neck cancer patients: the influence of hydrogen peroxide. Mol Cell Biochem 201; 440: 139-145. https://doi. org/10.1007/s11010-017-3162-2

[20] HU Z, ZENG Q, ZHANG B, LIU H, WANG W. Promotion of $\mathrm{p} 53$ expression and reactive oxidative stress production is involved in zerumbone-induced cisplatin sensitization of non-small cell lung cancer cells. Biochimie 2014; 107 Pt B: 257-262. https://doi.org/10.1016/j.biochi.2014.09.001

[21] KOSMIDER A, CZEPIELEWSKA E, KURAS M, GULEWICZ K, PIETRZAK W et al. Uncaria tomentosa Leaves Decoction Modulates Differently ROS Production in Cancer and Normal Cells, and Effects Cisplatin Cytotoxicity. Molecules 2017; 22. https://doi.org/10.3390/molecules22040620

[22] HUANG D, LI C, ZHANG H. Hypoxia and cancer cell metabolism. Acta Biochim Biophys Sin (Shanghai) 2014; 46: 214-219. https://doi.org/10.1093/abbs/gmt148

[23] GILKES DM, SEMENZA GL, WIRTZ D. Hypoxia and the extracellular matrix: drivers of tumour metastasis. Nat Rev Cancer 2014; 14: 430-439. https://doi.org/10.1038/nrc3726

[24] MARCU LG, HARRISS-PHILLIPS WM, FILIP SM. Hypoxia in head and neck cancer in theory and practice: a PETbased imaging approach. Comput Math Methods Med 2014; 2014: 624642. https://doi.org/10.1155/2014/624642

[25] BARSOUM IB, SMALLWOOD CA, SIEMENS DR, GRAHAM CH. A mechanism of hypoxia-mediated escape from adaptive immunity in cancer cells. Cancer Res 2014; 74: 665674. https://doi.org/10.1158/0008-5472.CAN-13-0992

[26] AKAKURA N, KOBAYASHI M, HORIUCHI I, SUZUKI A, WANG J et al. Constitutive expression of hypoxia-inducible factor-1alpha renders pancreatic cancer cells resistant to apoptosis induced by hypoxia and nutrient deprivation. Cancer Res 2001; 61: 6548-6554.

[27] GUO Q, LAN F, YAN X, XIAO Z, WU Y et al. Hypoxia exposure induced cisplatin resistance partially via activating p53 and hypoxia inducible factor-1alpha in non-small cell lung cancer A549 cells. Oncol Lett 2018; 16: 801-808. https:// doi.org/10.3892/ol.2018.8767

[28] RAVI R, MOOKERJEE B, BHUJWALLA ZM, SUTTER $\mathrm{CH}, \mathrm{ARTEMOV} \mathrm{D}$ et al. Regulation of tumor angiogenesis by 553 -induced degradation of hypoxia-inducible factor 1alpha. Genes Dev 2000; 14: 34-44.

[29] VON WAHLDE MK, HULSEWIG C, RUCKERT C, GOTTE M, KIESEL L et al. The anti-androgen drug dutasteride renders triple negative breast cancer cells more sensitive to chemotherapy via inhibition of HIF-1alpha-/VEGF-signaling. Gynecol Endocrinol 2015; 31: 160-164. https://doi.or g/10.3109/09513590.2014.971235

[30] SABHARWAL SS, SCHUMACKER PT. Mitochondrial ROS in cancer: initiators, amplifiers or an Achilles' heel? Nat Rev Cancer 2014; 14: 709-721. https://doi.org/10.1038/nrc3803

[31] SOSA V, MOLINE T, SOMOZA R, PACIUCCI R, KON$\mathrm{DOH} \mathrm{H}$ et al. Oxidative stress and cancer: an overview. Ageing Res Rev 2013; 12: 376-390. https://doi.org/10.1016/j. arr.2012.10.004 
[32] ZHAO Y, QU T, WANG P, LI X, QIANG J et al. Unravelling the relationship between macroautophagy and mitochondrial ROS in cancer therapy. Apoptosis 2016; 21: 517-531. https://doi.org/10.1007/s10495-016-1236-3

[33] VALKO M, RHODES CJ, MONCOL J, IZAKOVIC M, MAZUR M. Free radicals, metals and antioxidants in oxidative stress-induced cancer. Chem Biol Interact 2006; 160: 1-40. https://doi.org/10.1016/j.cbi.2005.12.009
[34] SO H, KIM H, LEE JH, PARK C, KIM Y et al. Cisplatin cytotoxicity of auditory cells requires secretions of proinflammatory cytokines via activation of ERK and NF-kappaB. J Assoc Res Otolaryngol 2007; 8: 338-355. https://doi.org/10.1007/ s10162-007-0084-9 